suggests with some reason that both the so-called presystolic and systolic murmurs owe their existence to regurgitation through the mitral orifice. It seems to me to be a mistake, however, to consider that the diastolic murmurs are directly connected with stenosis of the mitral valve. They appear to be merely varieties of that dull sound so frequently heard in the diastolic period of the cardiac beat in various morbid conditions of the heart that has been called not inappropriately " the third sound." Until the method of production of this "third sound" is clearly understood it seems to me that reference to the diastolic sounds of mitral stenosis will complicate rather than elucidate the question under discussion.

I am, Sirs, yours faithfully, THEODORE FISHER.

Jan. 12th, 1900. TH.

\section{OPERATIONS FOR ACUTE APPENDICITIS.}

\section{To the Editors of THE LANCET.}

SIRS, - I am glad to find that so careful and experienced a surgeon as Mr. Keetley, in his letter in your last issue with reference to the points raised by Mr. Moullin and myself, is substantially in accord with me with regard to the nature of the operation that should be performed for most cases of acute appendicitis. With most of what Mr. Keetley says I entirely agree. He evidently recognises that it is not desirable to open the peritoneal cavity and the abscess without regard to the limiting adhesions. This is the essential point which I ventured to urge in my letter in THE LANCET of Dec. 30th, 1899 (p. 1857). Although Mr. Keetley claims that his method of operation may safely be adopted, even on the first day of an attack, he says later that he has no experience of any operation performed within the first 36 hours. He does not tell us at what stage he does usually operate. He objects to a rule of waiting until the fifth day. So should I, and I have carefully refrained from laying down any such hard-and-fast rule, although $I$ do think that the necessity for operation seldom arises before that period. Each case must be judged on its own merits and the operation should, I think, be performed as soon as the surgeon believes that he can reach the abscess without opening the surrounding healthy (and absorbing) peritoneum. Mr. Keetley, with gentle sarcasm, seems to imply that I adrocate letting the abscess alone indefinitely, but that is certainly not my practice. The earliest period at which I have been able to open the abscess through the adherent peritoneum has been the third day, but in most cases the operation can, I believe, not be performed with safety at this period. I see no objection to opening the nonadherent peritoneum for purposes of gentle exploration, if it be thought necessary. I sometimes do this, but I never open the abscess through the same incision. I confess I do not see wherein the operation that Mr. Keetley recommends differs essentially from that recommended and practised by myself and many other surgeons. Mr. Keetley probably goes a little more deeply into the iliac fossa than I should and probably operates somewhat earlier. When he speaks of carrying his dissection "towards the pelvio brim" he certainly goes further than I should. I should have thought that the manipulation necessary for such a deep dissection would have involved no little risk of rupturing the unopened intraperitoneal abscess (abscesses connected with the appendix are, of course, almost always intraperitoneal). The presence of a mass of inflamed tissues in the iliac fossa would not, in my opinion, render such a deep dissection particularly easy. Mr. Keetley seems to think that his operation is peculiar in that thereby he goes to meet the pus instead of waiting for the pus to come to him. But if he will refer to my previous letter he will see that I speak of opening the adherent peritoneum. I do not advocate waiting until the pus has come through the peritoneum. Mr. Keetley does not touch upon the interesting question which cases should be operated upon without regard to the adhesions. That there are such cases no one, I suppose, would deny. although for my own part I believe them to be rare. It is not my intention, however, to raise this question now.

Mr. Keetley expresses his belief that "more cases operated on from the fifth to the tenth day are fatal than any others." But this I venture to think depends entirely upon what operation is done. Fowler's ${ }^{1}$ statistics of 49 cases operated

1 Annals of Surgery, 1894, p. 565. upon from the fourth to the seventh day inclusive show 21 deaths; these were all cases of operation without regard to adhesions and would confirm Mr. Keetley in his belief. But the statistics from St. Bartholomew's Hospital, which I quoted in my previous letter, of operations performed in some such manner as that advocated by Mr. Keetley or by myself, tell strongly in the opposite direction. But Mr. Keetley apparently does not believe in statistics. For my own part, 1 think they may be of much value, provided that they are ancurate, that they deal with consecutive cases, and that they embrace a sufficiently large number of such cases.

I am, Sirs, yours faithfully,

Wimpole-street, Jan. 16th, 1900. JAUES BERRY.

\section{"DEATHS UNDER CHLOROFORM." To the Editors of THE LANCET.}

SIRS, - The letter of Lieutenant Clayton Lane, I.M.S., in THE LANCET of Jan. 13th, p. 132, expresses opinions exactiy similar to those which appeared in a letter of mine in THE LANCET of July 1st, 1899, p. 53. Since the publication of that letter various letters have appeared in praise of Krobne and Sesemann's inhaler, none of which have convinced me. Nor has conviction been carried to my mind by the bundle of pamphlets sent me last July by Messrs. Krohre and Sesemann claiming innumerable advantages for their inhaler. In fact, if a medical man believed all the statements in these pamphlets it would be easy for him to convince himself that administration of chloroform by any other method must be very little short of criminal.

I am, Sirs, yours faithfully,

Plymouth, Jan. 14th, $1900 . \quad$ C. HAMILTON WHITEFORD.

\section{"THE CONEERENCE AT NEWCASTLE AND} THE MIDWIFERY QUESTION."

\section{To the Editors of THE LANCET.}

SIRs,-Your ccrrespondent Mr. Charles E. S. Flemming has been good enough to lay before me in THe LANCET of Jan. 13th, p. 133, some points which have arisen from my letter which appeared in your issue of Jan. 6th, and I thank him. It is only through the bringing up and examination of other aspects of any vexed question that a right and final finding can be crystallised. I bave pleasure in answering bim by means of the rough sketch of a scheme which I trust will also serve to explain still other points that might crop up.

Scheme for the Working of Mr,dical Practitioner plus Obstetric Nurse in Place of Midwife.

1. Both medical practitioner and obstetric nurse to be responsible according to following arrangement, and also according to further regulations which need not be introduced in this sketch.

2. Patients to pay medical practitioner a fee for visiting of $3 \mathrm{~s} .6 \mathrm{a}$. to 78. 6 d. (subject to carefully fixing under revised scheme). In case of poverty the fee to be paid by parish.

3. Obstetric nurse to attend virtually as medical practitioner"s assistant at the labour and afterwards.

4. Obstetric nurse to continue in attendance on labour and afterwards unless difficulties or complications arise, when she shall send for medical practitioner (just as midwives are expected to do and as assistant would do). If no complication or difficulty the obstetric nurse reports case to medical practitioner after a certain number of days and he will visit case.

5. Medical practitioner's fee plus obstetric nurse's fee should be about 5. Medical practitioner's fee plus obstetrio nurse's fee should be about equal former midwife's fee plus cost of common help usually require midwife system, for visits of obstetric nurse should render supplemidwife system, for visits of obstetric

6. Medical practitioner's fee shall be one for every class of case, normal 6. Medical practitioner's fee shall be one for every class of case, normal or complicated, the large percentage of normality making it well worth
his while, especially as he has his obstetric nurse under supervision and control in scheme, rendering carelessness unlikely

7. Medical practitioners of districts to be appointed annually; ts be advertised for and elected by boards of guardians, or councils, or committees.

8. All patients employing obstetric nurses must consent to visit of appointed medical practitioner at least once. They would be permitted to have consultation after this visit on paying for it in the ordinary way.

The above is only intended as a sketch of fundamental principles, which are only at the moment necessary to consider, and only such details are put in as permit the principles to be advanced or as support them. The following regulations as affecting the obstetric nurse are also merely intended as an indication of principles.

Regulations as affecting Obstetric Nurse.

1. Obstetric nurse shall not penetrate vulva with fingers, except perhaps under rare circumstances indicated in training. 